\title{
Bağlayıcı Olarak CMC Kullanımının Kromit Konsantrelerinden Üretilen Soğuk Bağlı Kompozit Peletlerin Mukavemetine Etkisi
}

\author{
Uğur ÇALIGÜLÜ ${ }^{*}$, Mustafa BOYRAZLI², Selçuk KARATAŞ², \\ Ercan ÇAKIR ${ }^{1}$, Ali KESKIN ${ }^{3}$ \\ ${ }^{I}$ Fırat Üniversitesi, Teknoloji Fakültesi, Metalurji ve Malzeme Mühendisliği Bölümü, 23000, Elazı̆̆ \\ ${ }^{2}$ Firat Üniversitesi, Mühendislik Fakültesi, Metalurji ve Malzeme Mühendisliği Bölümü, 23000, Elazlğ \\ ${ }^{3}$ Etikrom Yildırım Holding, Elazı $\breve{g}$ \\ (ORCID: 0000-0003-4862-7219) (ORCID: 0000-0002-2340-6703) (ORCID: 0000-0002-2340-6703)
}

(ORCID: 0000-0003-2722-4277) (ORCID: 0000-0003-3312-2576)

\begin{abstract}
$\ddot{\mathbf{O z}}$
Kompozit pelet ya da briket kelimesi, genellikle bünyesinde toz cevher ya da konsantre, cüruf yapıcı ve katı redükleyici madde (kömür, kok vb.) içeren pelet veya briketler için kullanılan bir terimdir. Bunlar üretildikten sonra, bir sonraki aşamada gerekli işlemler için, düşük sıcaklıklarda $\left(25-300^{\circ} \mathrm{C}\right)$ mukavemet kazandırılmış peletlerdir. Bu pelet ya da briketler, alternatif demir çelik üretim yöntemlerinden olan FASTMET veya ITMK3 üretim prosesleri için kullanılan bir malzemedir. $\mathrm{Bu}$ çalışmada; ETIKKROM Yıldırım Holding'den sağlanan, yaklaşık $\% 52 \mathrm{Cr}_{2} \mathrm{O}_{3}$ tenörlü kromit konsantresi, redükleyici olarak kok tozu ve flaks malzemesi olarak $\mathrm{Ca}(\mathrm{OH})_{2}$, peletleri oluşturan taneciklerin birbirine bağlanmasını sağlayan karboksi metil selüloz (CMC) kullanılarak elde edilen kromit peletlerinin, elektrik ark firınlarına beslenmeden önce ön redüksiyon işlemi için gerekli mukavemete sahip olması amacıyla, kompozit pelet üretiminin gerçekleştirilmesi amaçlanmıştır. Deneylerde; konsantreye önce sadece $\% 0,5, \% 1$ ve $\% 2$ oranlarında CMC ilave edilmiş ve üretilen peletlerin yaş pelet düşme sayısı ile kuru mukavemet değerlerine bakılmıştır. Buna göre; CMC oranının artmasıyla, mukavemet ve yaş pelet düşme sayısının arttığı gözlenmiş, $\% 2 \mathrm{CMC}$ ilave edilen peletlerin 90 dakika, $200^{\circ} \mathrm{C}$ sicaklıkta bekletilmeleri sonucu 39,36 kg-kuvvet/Pelet (386 N/Pelet) kuru mukavemet değerinin elde edildiği görülmüştür. \%2 CMC ilave edilerek üretilen peletlerini yaş pelet düşme sayılarının $23-27$ düşme $/ 45 \mathrm{~cm}$ arasında değiştiği gözlenmiştir. \%2 CMC, \%20 kok tozu ve $\% 4 \mathrm{Ca}(\mathrm{OH})_{2}$ ilave edilerek üretilen kompozit peletlerin mukavemet değerlerinin, 73,9 kg-kuvvet/Pelet (725 N/Pelet) kuru mukavemet değerine sahip oldukları tespit edildi. Elde edilen bu mukavemet değerleri, soğukta sertleşen pelet mukavemet standartlarının (250-300 N/Pelet ) üzerinde bir değerdir.
\end{abstract}

Anahtar kelimeler: Soğukta Sertleşen Pelet, Kromit, CMC, Kuru Pelet Mukavemeti.

\section{The Effect of Using CMC as a Binder on the Strength of Cold Bonded Composite Pellets Produced from Chromite Concentrates}

\begin{abstract}
The word composite pellet or briquette is a term generally used for pellets or briquettes containing powder ore or concentrate, slag maker, and solid reducing agent (coal, coke, etc.). After these are produced, they are pellets that have been strengthened at low temperatures $\left(25-300^{\circ} \mathrm{C}\right)$ for the next stages. These pellets or briquettes are materials which was used for sponge iron production processes, one of the alternative iron and steel production methods. This study; as using Chromite concentrate with approximately $52 \% \mathrm{Cr}_{2} \mathrm{O}_{3}$ grade supplied from ETIKROM Yıldırım Holding, coke powder as reducing agent and $\mathrm{Ca}(\mathrm{OH})_{2}$ as slag maker, and carboxy methyl cellulose (CMC) that has contributed bonding the chromite particles to each other to form were aimed to produce chromite pellets to which have strength necessary in order to pre-reduction before feeding to electric arc furnace. In the experiments; first, only at the rate of $0.5 \%, 1 \%$ and $2 \% \mathrm{CMC}$ was added to the concentrate and the wet pellet fall number and dry strength values of the produced pellets were examined. According to this; As the CMC ratio increased, it was observed that the dry strength of pellets and wet pellet falling number increased base on ratio of CMC, and the dry strength of pellets in which added $2 \%$ CMC and dried at $200^{\circ} \mathrm{C}$ for 90 minutes was obtained $39.36 \mathrm{~kg}$-force/Pellet (386 N / Pellet). It was observed that the number of wet pellet falling of pellets produced by adding 2\% CMC varied between 23-27 drops / $45 \mathrm{~cm}$. It was determined that the strength values of composite pellets produced by adding $2 \% \mathrm{CMC}, 20 \%$ coke powder and $4 \% \mathrm{Ca}(\mathrm{OH})_{2} \mathrm{had} 73.9 \mathrm{~kg}-$ force / Pellet (725 N / Pellet) dry strength value. The values of strength obtained are higher than the cold hardening pellet strength standards (250-300 N/Pellet).
\end{abstract}

Keywords: Cold-Hardening Pellet, Chromite, CMC, Dry Pellet Strength.

*Sorumlu yazar: ugurcaligulu@gmail.com

Gelis Tarihi: 31.01.2021, Kabul Tarihi: 01.04.2021 


\section{Giriş}

Kromit minerali, metalik kromun, krom bileşiklerinin ve kimyasallarının tek bilinen minerali olup, spinel grubuna ait bir oksit mineralidir. Kromit yatağına bağlı olarak değişen oranlarda magnezyum, demir, alüminyum ve krom içermekte ve $\mathrm{FeCr}_{2} \mathrm{O}_{4}$ veya $\left(\mathrm{Fe}^{2+}, \mathrm{Mg}\right)\left[\mathrm{Cr}, \mathrm{Al}, \mathrm{Fe}^{3+}{ }_{2} \mathrm{O}_{4}\right.$ şeklinde gösterilmektedir. Kafesteki toplam ve nispi $\mathrm{Cr}$ ve $\mathrm{Fe}$ miktarlarında büyük farklılıklar, kromit yataklarının farklı jeolojik ve coğrafi dağılımına bağlı olarak meydana gelir[1-4]. Dünyada üretilen kromit cevherinin \% 90'ından fazlası metalurji sanayiinde ferrokrom $(\mathrm{FeCr})$ üretiminde, üretilen ferrokrom ( $\mathrm{FeCr}$ )'unda yaklaşık \% 90`1 paslanmaz çelik sektöründe kullanılmaktadır. Bu nedenle uluslararası piyasalarda krom cevheri genellikle metalurjik özelliğine göre alınıp satılmaktadır.

Türkiye dünya kromit madenciliğinde $\% 6$ paya ve 25 milyon ton rezerve sahiptir [5]. Türkiye'de kromit talebi daha çok metalürjik tip cevherlerle karşılanmaktadır. Kromit cevheri, birincil maden ihracatında Türkiye'nin başlıca gelir kaynaklarından biridir. Üretilen kromit cevheri en çok demir-çelik (yaklaşık\% 85) ve kimya endüstrisi (yaklaşık\% 15) tarafından tüketilmektedir [4].

Cevherlerin veya konsantrelerin peletlenmesi anlamı bir taraftan ince taneciklerin su, gerektiği takdirde bağlayıcı madde ile topaklanarak küresel bir şekil almalarını diğer taraftan bu yaş peletlerin termik sertleştirme işlemini kapsar. Cevherin veya konsantrelerin peletlenebilmeleri için tane büyüklüklerinin, \% 50-80' nin 0,045 mm (325 mesh)' nin altında olması istenir. İnce taneli cevherlerin topaklanarak küresel bir şekil almaları tambur, tabla veya kesik konilerde olur [7].

Soğuk bağlı peletler 250-300 N/Pelet basınç dayanımına, 7-10 kere/1 m düşme dayanımına, $\% 98$ 'in üzerinde aşınma direncine $(+3 \mathrm{~mm})$ sahiptir. Soğuk bağlı peletlerin porozitesi genellikle \%2123 olup yüksek sicaklıklarda $\left(1200-1300^{\circ} \mathrm{C}\right)$ pişirilen peletlerden belirgin bir şekilde büyüktür. Soğuk bağlı peletler her ne kadar diğerine göre daha düşük mekanik dayanıma sahip olsalar bile indirgenme davranışları (indirgenebilirlik, şişme oranı) oksitli ortamda pişirilen peletlere oranla daha üstündür. Soğuk bağlı peletlerin mükemmel bir tarzda indirgenebilmeleri onların büyük porozitelerine bağlıdır [89].

Kompozit pelet terimi genellikle ince cevher veya konsantre, flaks ve karbonlu madde (kömür, kok, odun kömürü) içeren peletler için kullanılır. Bunlar, oda sıcaklığı veya civarında taşınması için yeterli mukavemet kazandırılmış peletlerdir. Reaksiyon hızlarından dolayı kompozit peletlerin kullanılabilmesi için iki temel özelliğe dikkat etmek gerekmektedir. Bunlardan ilki pelete olan is1 transferine bağlıdır. İkincisi de karbonlu peletlerin pişirilememesinden dolayı ya soğuk bağlı olarak kullanılması ya da redüksiyon prosesi esnasında peletlerin üzerine hiçbir yükün binmemesi sağlanmasıdır. Soğuk bağlı peletler portland çimentosu veya yüksek firın cürufu ve kireç karışımı ile karıştırılıp kurutulabilir [10]. Kompozit peletler genellikle demir tanesi üretim prosesleri için kullanılan bir malzemedir.

$\mathrm{Bu}$ çalışmada, alternatif demir çelik üretiminde kullanılan peletleme proseslerine benzer bir şekilde, kromit konsantresi, kok tozu ve flaks kullanılarak soğukta sertleştirilmiş kompozit pelet üretiminin gerçekleştirilmesi amaçlanmıştır.

\section{Materyal ve Metot}

Çalışmalarda, Elazı̆̆g-Kovancılar ilçesinde bulunan ETİKROM Yıldırım Holding'den temin edilen kromit konsantresi ve kok tozu, piyasadan satın alma yoluyla temin edilen $\mathrm{Ca}(\mathrm{OH})_{2}$ ve bağlayıcı olarak da yine satın alma yoluyla temin edilmiş olan sodyum karboksi metil selüloz (CMC) kullanılarak soğukta sertleşebilen kompozit peletlerin üretilmesi hedeflenmiştir.

Deneysel çalışmalarda pelet üretimi aşamasında bağlayıcı olarak kullanılan CMC, \%99,5 saflıkta olup, teknik CMC ve etil alkolün ekstraksiyonundan türetilir. Krem rengi toz olup, suda kolayca çözünebilen yarı sentetik polimer bir malzemedir (Şekil 1) [11].

Soğukta sertleşen kompozit pelet üretmek için, özel kompozisyonlar halinde hesaplanan miktarlarda hazırlanan malzemeler ve bağlayıcı, pelet kekinin içine ilave edilmiş, hazırlanan bu harman cevherle birlikte cam bir kavanoz içinde, özel aparatı bir mikser yardımıyla 10 dakika karıştırılmıştır. Hazırlanan karışımın küresel pelet formunu alışı, Şekil 2'de gösterilen laboratuvar ölçekli peletleme cihazında gerçekleştirilmiştir. Peletleme cihazı $35 \mathrm{~cm}$ çapında yatayla $45^{\circ}$ 'lik açı yapan, hız ve titreşim kontrollü bir cihazdır. Yaklaşık 1-1,5 kg malzeme alabilen titreşimli bir haznesi mevcuttur. Yaş pelet ölçümlerinin kolayca yapılabilmesi için cihaz çelik bir plaka üzerine monte edilmiştir. Pelet üretimi için, 
önce diskin yüzeyine su püskürtülerek disk yüzeyi nemlendirilmiş, daha sonra titreşim cihazı çalıştırılarak toz malzemenin yavaş yavaş diskin yüzeyine yapışması sağlanmıştır. Disk yüzeyi tamamen malzemeyle kaplandıktan sonra pelet çekirdeklerinin oluşumu ve büyümesi gerçekleştirilmiştir (Şekil 3). Pelet tamburunun dönme hızı, besleyicinin besleme hızı ve süresi hazırlık aşamalarında yapılan çeşitli deneyler sonucunda belirlenmiştir. Oluşan çekirdekler su ile hafifçe nemlendirilerek daha büyük çapta peletlerin oluşumu sağlanmıştır. Peletleme tamburunda boyutu büyüyen peletler belirli sürelerde tamburdan alınarak yaklaşık 11-13 mm çaplı peletler gerekli testler için ayrılmıştır. Topaklama tambur ya da disklerinden elde edilen ham peletin, 1sısal işlemin uygulanacağı bölgeye kadar taşınması sırasında kırılmaması için gerekli dayanımda olup olmadığının kontrolü için yapılan teste, yaş pelet düşme sayısı adı verilir. En az 10 adet ham pelet alınıp çatlayıncaya kadar $45 \mathrm{~cm}$ 'den çelik bir plaka üzerine serbest halde bırakılarak, yaş pelet düşme sayısı belirlenmiştir. Fiziksel testlerde önce yaş peletler üzerinde yaş pelet düşme sayısı testleri yapılmıştır.

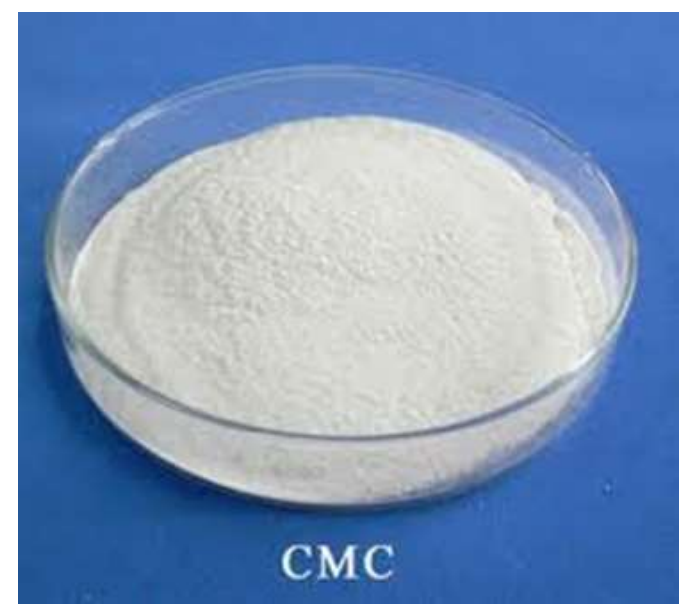

Şekil 1. Karboksi Metil Selülöz [11]

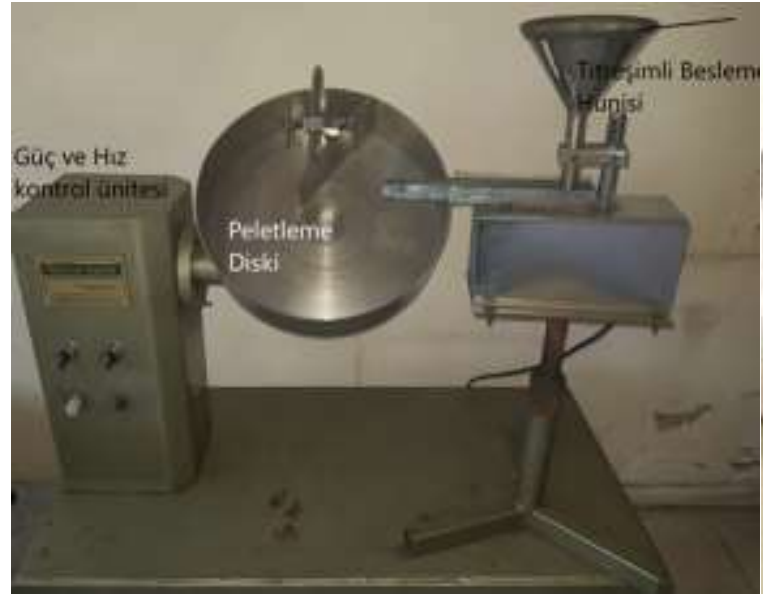

Şekil 2. Laboratuvar ölçekli peletleme diski

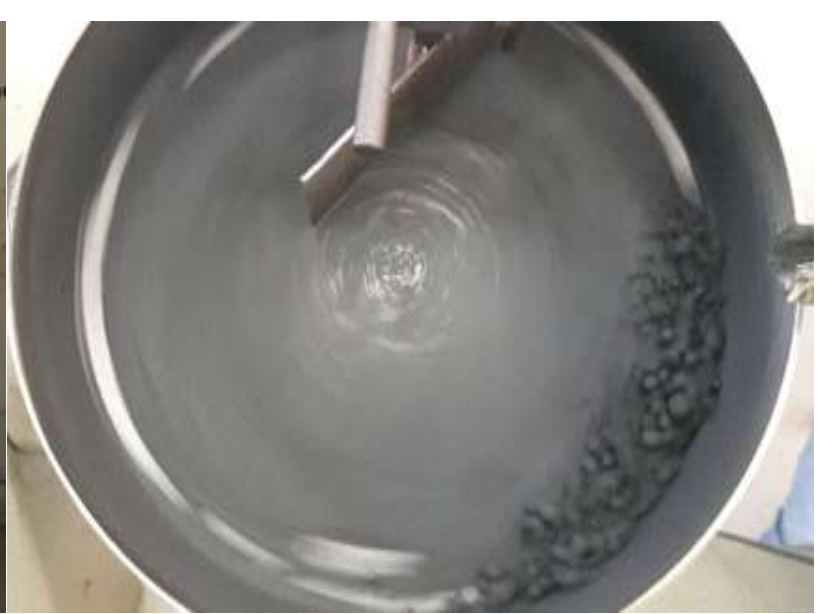

Şekil 3. Çekirdeklerin oluşumu ve büyümesi

Disk üzerinden alınan 11-14 mm çaplı peletlerin sertleştirme işlemleri sirkülasyonlu bir etüvde $100,150,200$ ve $250^{\circ} \mathrm{C}$ sicaklıklarda 30,60, 90 ve 120 dakika süre yapılmıştır. Kurutulan peletlerin mukavemeti, Şekil 4'de gösterilen hidrolik basma cihazında gerçekleştirilmiştir. Bu cihaz, peletin kırıldığı andaki yükü kaydedebilen bir cihazdır. 


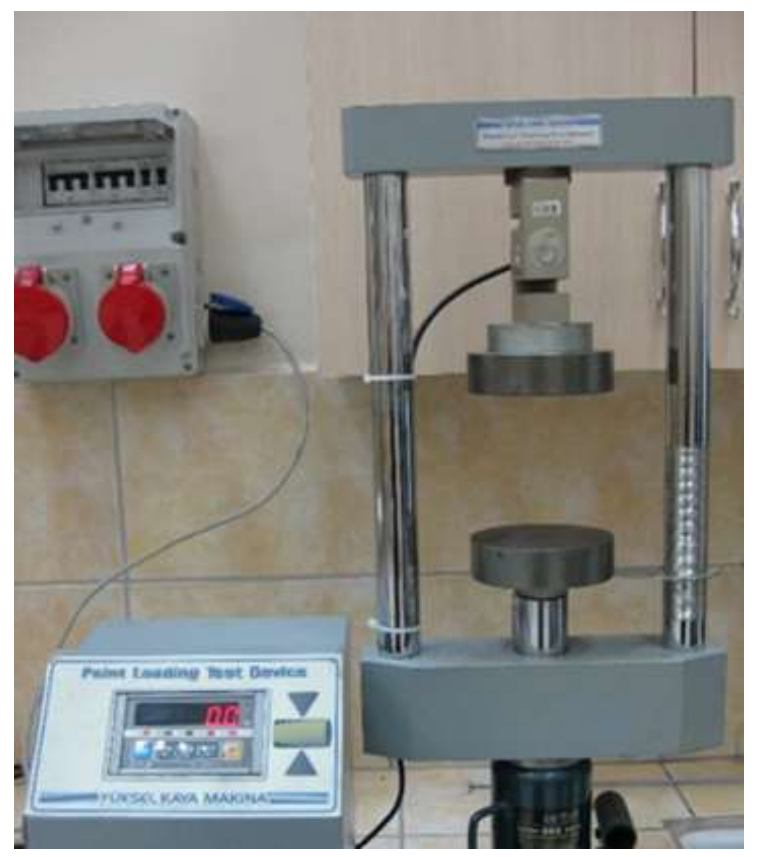

Şekil 4. Basma mukavemeti ölçüm cihazı.

\section{Bulgular ve Tartışma}

Deneylere başlamadan önce kromit cevheri, bağlayıcı (CMC) ilave edilmeksizin, bir karıştırıcı içine konularak yaklaşık 5 dakika kadar karıştırılıp, topaklaşmaların oluşması önlenmiş; ardından cevher içine ilave edilen bağlayıcı ile birlikte 10 dakika daha iyice karıştırılmıştır. Deneylerde konsantreye sadece $\% 0,5, \% 1$ ve $\% 2$ oranlarında CMC ilavesi yapılarak pelet özellikleri incelenmiştir. Yapılan deneylerde CMC oranı arttıkça mukavemet ve ham pelet düşme sayısının arttığı gözlenmiştir. Tablo 1 'de \%0,5 CMC, Tablo 2'de \%1 CMC ve Tablo 3'de ise \%2 CMC ilave edilerek üretilen kromit peletlerinin, kuru mukavemet değerlerindeki değişimler verilmektedir. Bu peletlerin kurutma sıcaklığına ve süresine bağlı olarak pelet mukavemetinde meydana gelen değişim grafikleri ise sirasıyla Şekil 5, Şekil 6 ve Şekil 7'de verilmiştir.

Tablo 1. \%0,5 CMC ilave edilerek üretilen peletlerin farklı sıcaklık ve sürelerde kurutulmaları sonucu kuru mukavemet değerleri.

\begin{tabular}{|c|c|c|c|c|c|c|}
\hline $\begin{array}{l}\text { Bağlayıcı } \\
\text { Miktarı } \\
(\%)\end{array}$ & $\begin{array}{l}\text { Kurutma } \\
\text { Sicakllığ }\left({ }^{\circ} \mathrm{C}\right)\end{array}$ & $\begin{array}{l}\text { Kurutma } \\
\text { Süresi } \\
\text { (dakika) }\end{array}$ & $\begin{array}{l}\text { Ortalama } \\
\text { Basma } \\
\text { Dayanımı } \\
\text { (N/pelet) }\end{array}$ & $\begin{array}{l}\text { Kurutma } \\
\text { Sicakllğg }\left({ }^{\circ} \mathrm{C}\right)\end{array}$ & $\begin{array}{l}\text { Kurutma } \\
\text { Süresi } \\
\text { (dakika) }\end{array}$ & $\begin{array}{l}\text { Ortalama } \\
\text { Basma } \\
\text { Dayanımı } \\
(\mathrm{N} / \text { pelet })\end{array}$ \\
\hline \multirow{8}{*}{0,5} & \multirow{4}{*}{100} & 30 & 54 & \multirow{4}{*}{200} & 30 & 75 \\
\hline & & 60 & 54 & & 60 & 148 \\
\hline & & 90 & 55 & & 90 & 169 \\
\hline & & 120 & 87 & & 120 & 185 \\
\hline & \multirow{4}{*}{150} & 30 & 56 & \multirow{4}{*}{250} & 30 & 92 \\
\hline & & 60 & 63 & & 60 & 53 \\
\hline & & 90 & 89 & & 90 & 54 \\
\hline & & 120 & 132 & & 120 & 48 \\
\hline
\end{tabular}




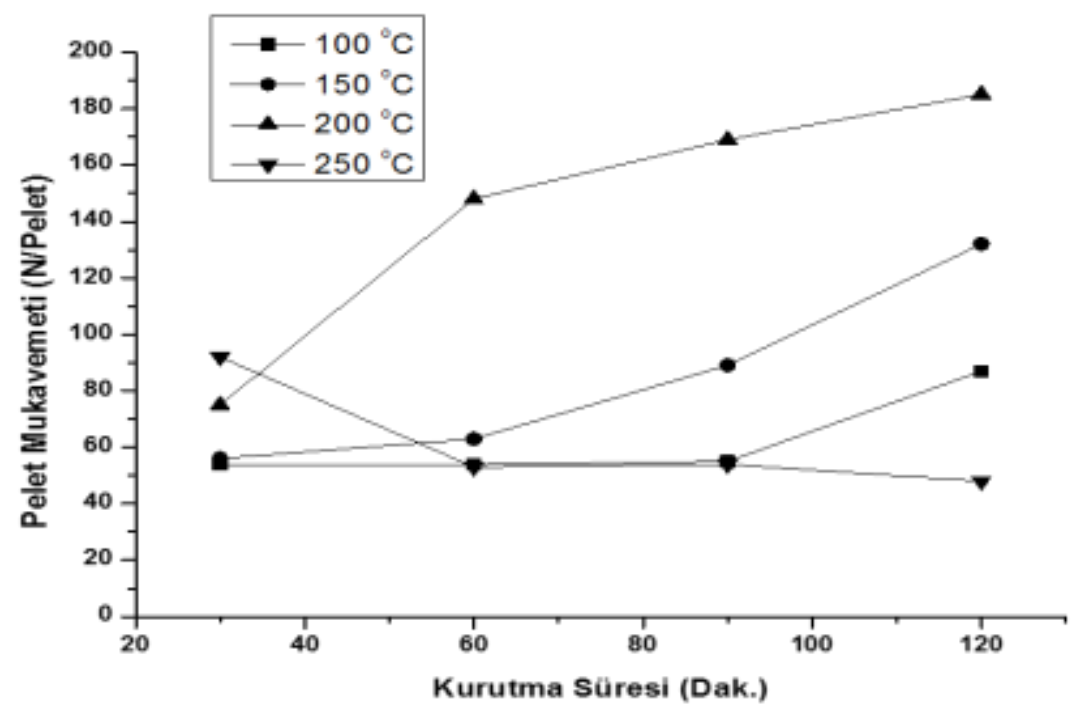

Şekil 5. \%0,5 CMC ilave edilerek üretilen kromit peletlerinin sıcaklık ve süreye bağlı kuru mukavemet değerlerindeki değişim.

Tablo 2. \%1 CMC ilave edilerek üretilen peletlerin farklı sıcaklık ve sürelerde kurutulmaları sonucu kuru mukavemet değerleri.

\begin{tabular}{|c|c|c|c|c|c|c|}
\hline $\begin{array}{l}\text { Bağlayıcı } \\
\text { Miktarı } \\
(\%)\end{array}$ & $\begin{array}{l}\text { Kurutma } \\
\text { Sicakllığ }\left({ }^{\circ} \mathrm{C}\right)\end{array}$ & $\begin{array}{l}\text { Kurutma } \\
\text { Süresi } \\
\text { (dakika) }\end{array}$ & $\begin{array}{l}\text { Ortalama } \\
\text { Basma } \\
\text { Dayanımı } \\
\text { (N/pelet) }\end{array}$ & $\begin{array}{l}\text { Kurutma } \\
\text { Sicaklı̆g }\left({ }^{\circ} \mathrm{C}\right)\end{array}$ & $\begin{array}{l}\text { Kurutma } \\
\text { Süresi } \\
\text { (dakika) }\end{array}$ & $\begin{array}{l}\text { Ortalama } \\
\text { Basma } \\
\text { Dayanımı } \\
\text { (N/pelet) }\end{array}$ \\
\hline \multirow{8}{*}{1} & \multirow{4}{*}{100} & 30 & 96 & \multirow{4}{*}{200} & 30 & 158 \\
\hline & & 60 & 108 & & 60 & 198 \\
\hline & & 90 & 104 & & 90 & 246 \\
\hline & & 120 & 141 & & 120 & 224 \\
\hline & \multirow{4}{*}{150} & 30 & 112 & \multirow{4}{*}{250} & 30 & 105 \\
\hline & & 60 & 152 & & 60 & 48 \\
\hline & & 90 & 184 & & 90 & 52 \\
\hline & & 120 & 212 & & 120 & 45 \\
\hline
\end{tabular}

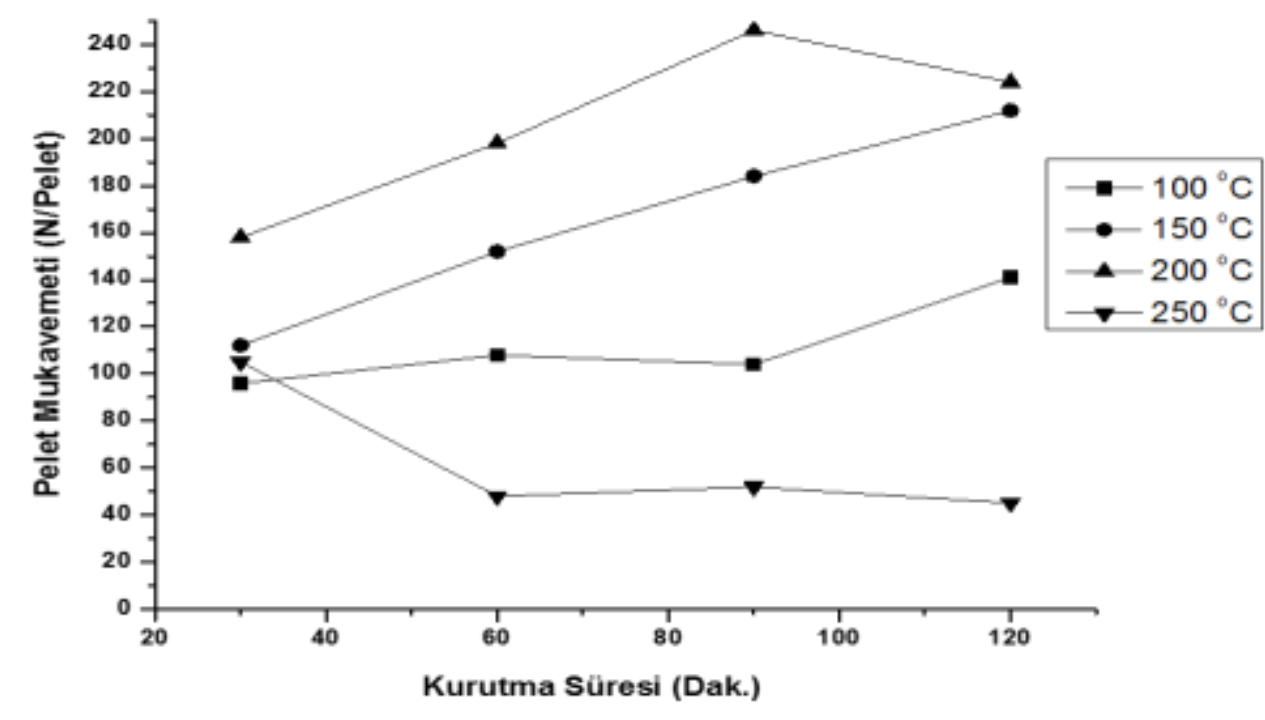

Şekil 6. \%1 CMC ilave edilerek üretilen kromit peletlerinin sıcaklık ve süreye bağlı kuru mukavemet değerlerindeki değişim. 
Tablo 3. $\% 2 \mathrm{CMC}$ ilave edilerek üretilen peletlerin farklı sıcaklık ve sürelerde kurutulmaları sonucu kuru mukavemet değerleri.

\begin{tabular}{|c|c|c|c|c|c|c|}
\hline $\begin{array}{l}\text { Bağlayıcı } \\
\text { Miktarı } \\
(\%)\end{array}$ & $\begin{array}{l}\text { Kurutma } \\
\text { Sicaklığ }\left({ }^{\circ} \mathrm{C}\right)\end{array}$ & $\begin{array}{l}\text { Kurutma } \\
\text { Süresi } \\
\text { (dakika) }\end{array}$ & $\begin{array}{l}\text { Ortalama } \\
\text { Basma } \\
\text { Dayanımı } \\
\text { (N/pelet) }\end{array}$ & $\begin{array}{l}\text { Kurutma } \\
\text { Sicaklığ }\left({ }^{\circ} \mathrm{C}\right)\end{array}$ & $\begin{array}{l}\text { Kurutma } \\
\text { Süresi } \\
\text { (dakika) }\end{array}$ & $\begin{array}{l}\text { Ortalama } \\
\text { Basma } \\
\text { Dayanımı } \\
\text { (N/pelet) }\end{array}$ \\
\hline \multirow{8}{*}{2} & \multirow{4}{*}{100} & 30 & 101 & \multirow{4}{*}{200} & 30 & 201 \\
\hline & & 60 & 134 & & 60 & 296 \\
\hline & & 90 & 163 & & 90 & 386 \\
\hline & & 120 & 196 & & 120 & 375 \\
\hline & \multirow{4}{*}{150} & 30 & 165 & \multirow{4}{*}{250} & 30 & 165 \\
\hline & & 60 & 254 & & 60 & 184 \\
\hline & & 90 & 299 & & 90 & 121 \\
\hline & & 120 & 324 & & 120 & 83 \\
\hline
\end{tabular}

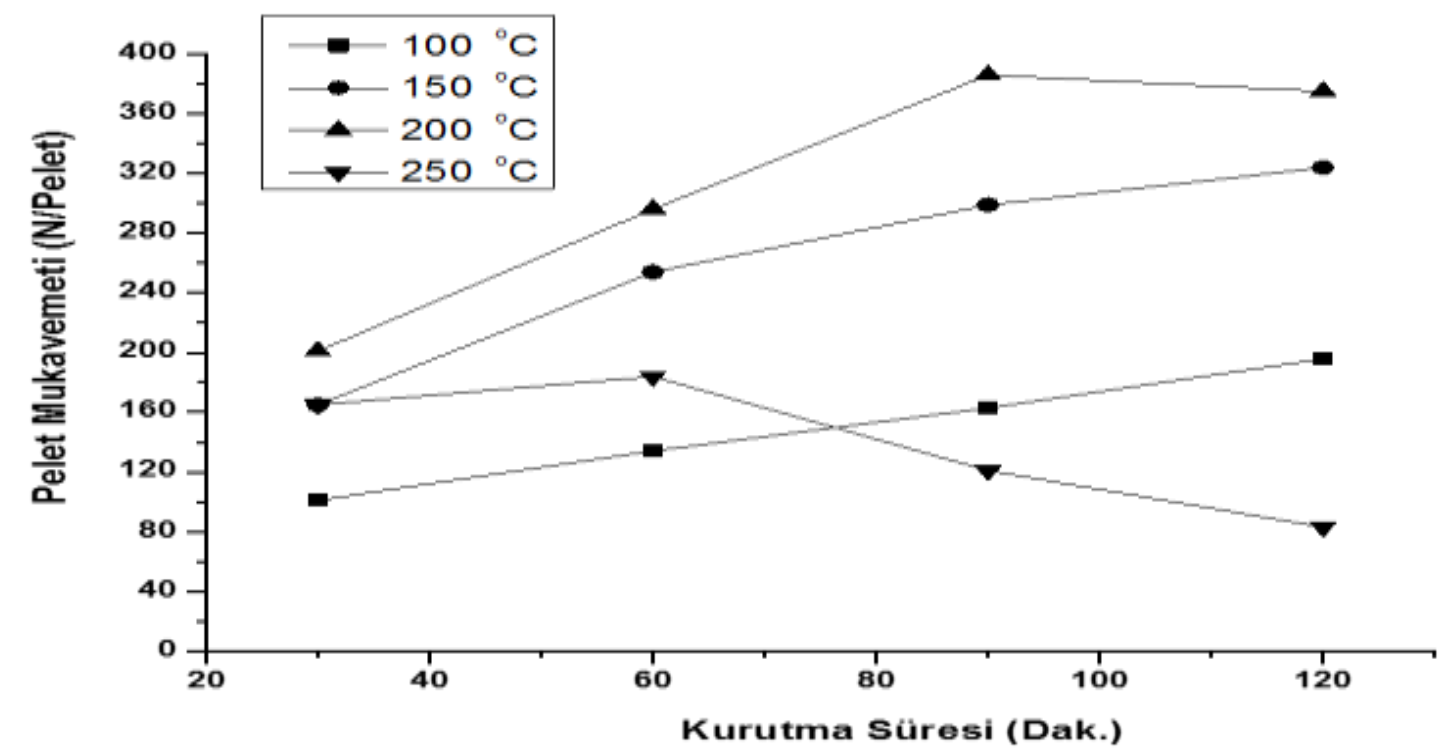

Şekil 7. \%2 CMC ilave edilerek üretilen kromit peletlerinin sıcaklık ve süreye bağlı kuru mukavemet değerlerindeki değişim.

Yapılan deneyler sonucu, ilave edilen CMC miktarına bağlı olarak yaş pelet düşürme sayısının da arttığı belirlenmiştir. \%0,5 CMC ilavesiyle yaş pelet düşürme sayıs1 5-8 düşme/45 $\mathrm{cm}$ arasında değişirken, \%2 CMC ilave edilen peletlerin yaş pelet düşürme sayılarının 23-27 düşme/45 cm olduğu tespit edilmiştir. Kurutma işlemine tabi tutulan peletlerin kuru mukavemet değerleri de aynı şekilde CMC miktarına bağlı olarak arttığı görüldü. Ancak $250^{\circ} \mathrm{C}^{\prime}$ de yapılan kurutma işleminde kuru mukavemet değerinde ani bir düşüşün olduğu görülmüştür. Organik malzemelerin $220^{\circ} \mathrm{Cnin}$ üzerindeki sıcaklıklarda bozunduğu ve bağlayıcılık vasfını yitirdiği hakkında literatürde yapılmış çalışmalar bulunmaktadır [10]. CMC'nin organik bir malzeme olmasından dolayı $200^{\circ} \mathrm{C}$ 'nin üzerindeki sıcaklıklarda bozunduğu ve bu nedenle kuru mukavemet değerlerinde bir düşüş olduğu sonucu ortaya çıkmaktadır. Kurutma işlemlerinde en yüksek mukavemet değeri \%2 CMC ilave edilerek üretilen peletlerin $200^{\circ} \mathrm{C}$ sicaklıkta 90 dakika kurutulmaları sonucu elde edilmiştir. Bu şartlarda üretilen peletlerin $386 \mathrm{~N} /$ Pelet mukavemet değerine sahip oldukları, bu mukavemet değerinin ise standartların üzerinde bir mukavemet değeri olduğu belirlenmiştir. En yüksek mukavemet değerinin elde edildiği \%2 $\mathrm{CMC}$ miktarı, kurutma sıcaklığ $\left(200^{\circ} \mathrm{C}\right)$ ve kurutma süresi sabit olarak belirlenip, kromit konsantresine farklı oranlarda kok ilave edilerek kompozit pelet üretimi gerçekleştirilmiştir. Burada amaç, kendinden redüklenebilen kromit peletlerini üretmektir. Tablo 4 ve Şekil 8 'de ilave edilen kok miktarına bağlı olarak pelet mukavemetindeki değişim değerleri ve grafiği verilmiştir. 
Tablo 4. \%2 CMC'nin yanı sıra farklı oranlarda kok ilave edilerek üretilen peletlerin kuru mukavemet değerleri.

\begin{tabular}{lllll}
\hline $\begin{array}{l}\text { Bağlayıc1 } \\
\text { Miktarı }\end{array}$ & $\begin{array}{l}\text { Kurutma } \\
\text { Sicaklığı } \\
\left({ }^{\circ} \mathrm{C}\right)\end{array}$ & $\begin{array}{l}\text { Kurutma } \\
\text { Süresi } \\
(\text { dakika })\end{array}$ & $\begin{array}{l}\text { İlave } \\
\text { Edilen Kok } \\
\text { Miktarı } \\
(\%)\end{array}$ & $\begin{array}{l}\text { Ortalama } \\
\text { Basma } \\
\text { Dayanımı } \\
(\mathrm{N} / \text { pelet })\end{array}$ \\
\hline \multirow{2}{*}{2} & \multirow{2}{*}{200} & \multirow{2}{*}{90} & 0 & 386 \\
& & & 10 & 425 \\
& & & 30 & 487 \\
\end{tabular}

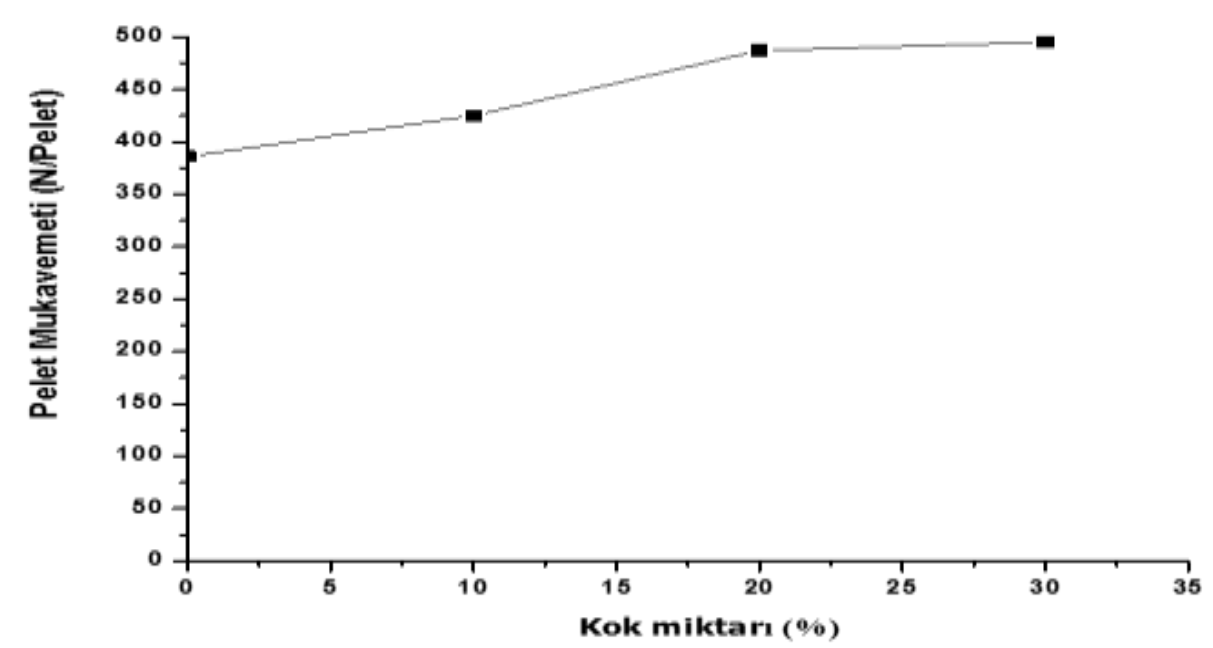

Şekil 8. \%2 CMC'nin yanı sıra farklı oranlarda kok ilave edilerek üretilen peletlerin kuru mukavemet değerlerindeki değişim $\left(\mathrm{T}=200^{\circ} \mathrm{C}, \mathrm{t}=90\right.$ dak. $)$.

Tablo 5 ve Şekil 9' dan görülebileceği gibi kok oranının artmasıyla mukavemet değerlerinde bir artış olduğu görülmektedir. Bu durum, kok bünyesinde bulunan ve kül diye adlandırılan bileşiklerin, bağlayıcılık vasıflarının da olduğu, ilave edilen CMC ile birlikte bu bileşiklerin kuru mukavemet değerlerine katkıda bulunduğu düşüncesini akla getirmektedir. Sonuçta kül denilen malzemenin bünyesinde, $\mathrm{Al}_{2} \mathrm{O}_{3}, \quad \mathrm{SiO}_{2}, \mathrm{CaCO}_{3}$ gibi bileşikler başta olmak üzere birçok inorganik bileşik bulunmaktadır. Çalışmalar esnasında, $\% 30$ kok ilave edilen peletlerde kok bünyesinde bulunan çok ince tane boyutlu tozlar pelet yüzeyini kaplamıştır. Bu nedenle \%20 kok, \%2 CMC, kurutma sıcaklığ ve kurutma süresi gibi parametreler sabit olarak alınmış, karşımın içerisine farklı oranlarda $\mathrm{Ca}(\mathrm{OH})_{2}$ ilavesi gerçekleştirilmiş ve sonuçlar Tablo 5 ve Şekil 9'da verilmiştir.

Tablo 5. \% 2 CMC ve \%20 kok'un yanı sıra farklı oranlarda $\mathrm{Ca}(\mathrm{OH})_{2}$ ilave edilerek üretilen peletlerin kuru mukavemet değerleri.

\begin{tabular}{lllllll}
\hline $\begin{array}{l}\text { Bağlayıc1 } \\
\text { Miktarı (\%) }\end{array}$ & $\begin{array}{l}\text { Kurutma } \\
\text { Sicaklığ }\left({ }^{\circ} \mathrm{C}\right)\end{array}$ & $\begin{array}{l}\text { Kurutma } \\
\text { Süresi } \\
\text { (dakika) }\end{array}$ & $\begin{array}{l}\text { Ilave Edilen } \\
\text { Kok Miktarı } \\
(\%)\end{array}$ & $\begin{array}{l}\text { İlave Edilen } \\
\mathrm{Ca}(\mathrm{OH})_{2} \\
\text { Miktarı }(\%)\end{array}$ & $\begin{array}{l}\text { Ortalama } \\
\text { Basma } \\
\text { Dayanımı } \\
\text { (N/pelet) }\end{array}$ \\
\hline & & & & 0 & 487 \\
2 & \multirow{2}{*}{200} & \multirow{2}{*}{90} & 20 & 1 & 623 \\
& & & 2 & 689 \\
\hline
\end{tabular}




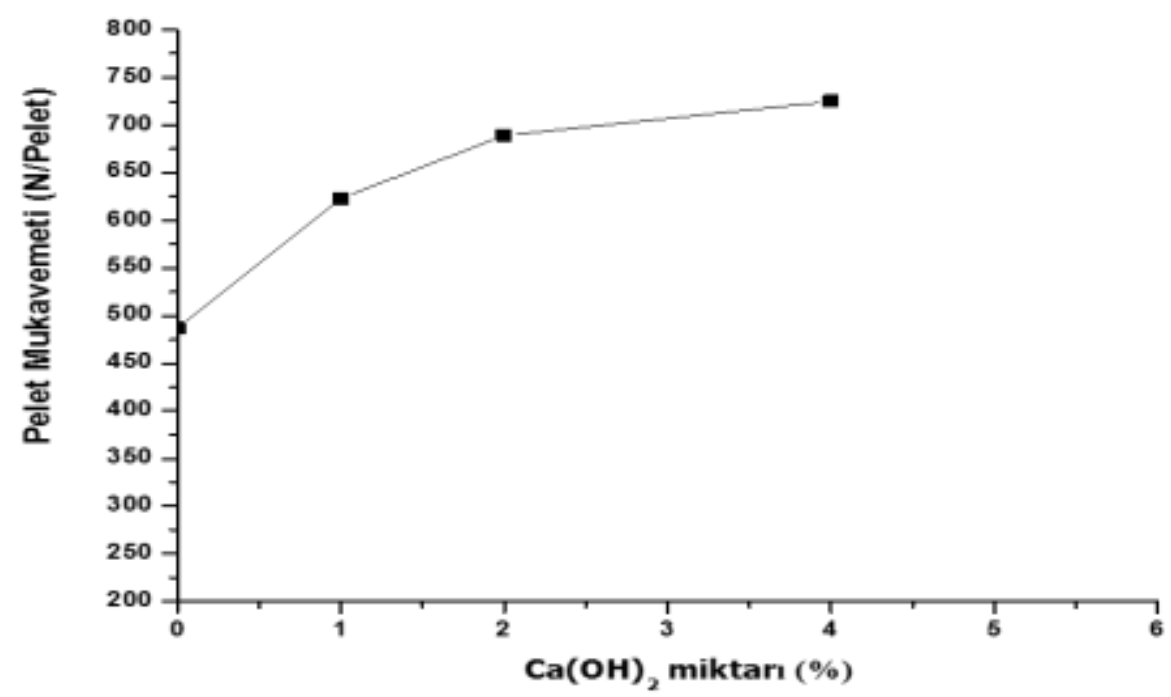

Şekil 9. \%2 CMC ve \%20 kok'un yanı sıra farklı oranlarda $\mathrm{Ca}(\mathrm{OH})_{2}$ ilave edilerek üretilen peletlerin kuru mukavemet değerlerindeki değişim $\left(\mathrm{T}=200^{\circ} \mathrm{C}, \mathrm{t}=90\right.$ dak. $)$.

Tablo 5 ve Şekil 9 birlikte incelendiğinde, $\operatorname{artan} \mathrm{Ca}(\mathrm{OH})_{2}$ oranının kuru pelet mukavemetinde 725 N/Pelet ( $72,4 \mathrm{Kg} /$ Pelet) gibi bir değer elde edildiği görülmüştür. Bu peletlerin yaş pelet düşürme sayıları 25-28 arasında değiştiği görülmüştür. $\mathrm{Ca}(\mathrm{OH})_{2}$ 'in sıcak pişirilmiş peletler de tek başına bağlayıcılık görevi yaptığı birçok çalışmada belirtilmiştir [12,13]. Ancak burada soğukta sertleştirilen kompozit pelet üretimi gerçekleştirilmiş ve standartların üzerinde bir mukavemet değeri elde edilmiştir.

$\mathrm{Ca}(\mathrm{OH})_{2}$ sönmemiş kirecin $(\mathrm{CaO})$ 'in, (rx-1)'e göre suyla reaksiyonu sonucu oluşur [14].

$\mathrm{CaO}+\mathrm{H}_{2} \mathrm{O} \rightarrow \mathrm{Ca}(\mathrm{OH})_{2}$

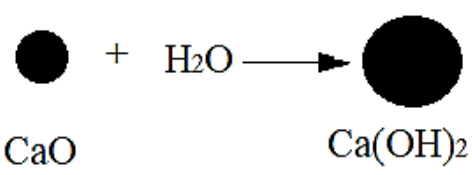

(a) $\mathrm{CaO}$ taneciğinin su ile reaksiyona girerek hacimce büyüyerek $\mathrm{Ca}(\mathrm{OH})_{2}$ 'ye dönüşümü $(\mathrm{rx}-1)$

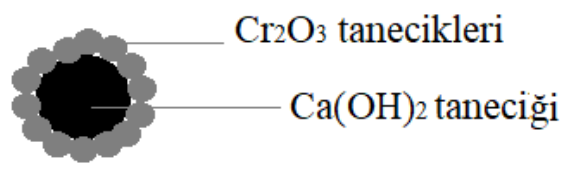

(b) $\mathrm{Ca}(\mathrm{OH})_{2}$ taneciğinin suyunda etkisiyle $\mathrm{Cr}_{2} \mathrm{O}_{3}$ taneciklerini etrafinda toparlaması

Şekil 10. $\mathrm{CaO}$ taneciğinin $\mathrm{H}_{2} \mathrm{O}$ ile reaksiyona girerek $\mathrm{Ca}(\mathrm{OH})_{2}$ oluşturması (a) ve $\mathrm{Ca}(\mathrm{OH})_{2}{ }^{\prime}$ nin $\mathrm{Cr}_{2} \mathrm{O}_{3}$ partiküllerini etrafinda toplayarak pelet oluşturması (b).

Sönmemiş kirecin hidrate olmas1, bünyesine suyu alarak hacimce genişlemesi demektir. Hacimce genişlemiş olan $\mathrm{Ca}(\mathrm{OH})_{2}$ tanecikleri, $\mathrm{CMC}$ ve kok bünyesinde bulunan inorganik bileșiklerle birlikte etrafinda kromit taneciklerini toplayarak Şekil 10'da temsili olarak gösterilen mekanizmaya benzer şekilde, kromit taneciklerinin bir araya gelerek topaklanmasını sağlayacaktır. $\mathrm{CaO}$ taneciğinin $\mathrm{H}_{2} \mathrm{O}$ ile reaksiyona girerek $\mathrm{Ca}(\mathrm{OH})_{2}$ oluşturması ve $\mathrm{Ca}(\mathrm{OH})_{2}$ 'nin $\mathrm{Cr}_{2} \mathrm{O}_{3}$ partiküllerini etrafinda toplayarak, kartopunun büyüme mekanizmasına benzer bir şekilde büyümesi sonucu peletlerin kuru ve yaş mukavemet değerlerinde standartların üzerinde bir değer elde edilmesi beklenen bir durum olmaktadır.

\section{Sonuç ve Öneriler}

$\mathrm{Bu}$ çalışmada, FASTMET ve ITMK3 Prosesinde kullanılan peletlerin üretimine benzer bir şekilde demir cevherleri yerine kromit cevherleri kullanılarak, soğukta sertleșebilen kompozit pelet üretiminin gerçekleştirilmesi amaçlanmıştır. Deneylerde Elazığ Kovancılar ilçesinde bulunan ETIKROM Yıldırım holding tesislerinden temin edilen -75 mikron boyutuna getirilen $\% 52 \mathrm{Cr}_{2} \mathrm{O}_{3}$ içeren 
kromit konsantresi kullanılmıştır. Bağlayıcı madde olarak, sodyum karboksi metil selüloz (CMC) ve $\mathrm{Ca}(\mathrm{OH})_{2}$ kullanılmıştır. Ayrıca, kendinden redüklenebilen peletler üretebilmek için de yine cevherle aynı boyuta getirilen (-75 mikron) kok kömürü kullanılmıştır. Peletlemede kullanılan bağlayıcı miktarı, kurutma sıcaklığı ve kurutma süresi gibi özellikler optimize edilerek en uygun parametreler belirlenmiştir. Bağlayıcı önce tek başına, sonra kok kömürü ilave edilerek ve en sonunda başka bir bağlayıcı ve flaks görevi yapabilecek olan $\mathrm{Ca}(\mathrm{OH})_{2}$ ile farklı oranlarda karıştırılarak peletler üretilmiş ve aşağıdaki sonuçlar elde edilmiştir.

- Karboksi Metil Selülozun (CMC) kromit cevherlerinin peletlenmesinde kullanılabilirliğini incelemek amaciyla önce sadece $\% 0,5, \% 1$ ve $\% 2$ oranlarında CMC ilave edilerek peletler üretilmiş, buradan alınan en yüksek mukavemet değerine göre belirlenen CMC miktarı, kurutma sicaklığı ve kurutma süresi sabit tutularak, cevherle beraber $\%, 10, \% 20$ ve $\% 30$ oranlarında kok karıştırılıp tekrar mukavemet değerlerine bakılmıştır. Kok oranının artmasıyla mukavemet değerlerinde bir artış olduğu görülmüştür. Bu durum, kok bünyesinde kül diye adlandırılan ve $\mathrm{Al}_{2} \mathrm{O}_{3}, \mathrm{SiO}_{2}, \mathrm{CaCO}_{3}$ gibi bileşikler başta olmak üzere birçok inorganik bileşiklerinde, $\mathrm{CMC}$ ile birlikte kuru mukavemet değerlerine katkıda bulunduğu düşüncesini akla getirmiştir. \%30 kok ilavesi ile üretilen peletlerde, kok bünyesinde bulunan çok ince tane boyutlu tozların pelet yüzeyini kapladığı görülmüştür.

- \%20 kok, \%2 CMC, kurutma sıcaklığı ve kurutma süresi gibi parametreler sabit olarak alınmış, karşımın içerisine farklı oranlarda $\mathrm{Ca}(\mathrm{OH})_{2}$ ilavesi yapılmış ve kuru mukavemet değerlerinin ilave edilen $\mathrm{Ca}(\mathrm{OH})_{2}$ oranına bağlı olarak arttı̆g ve $\% 4 \mathrm{Ca}(\mathrm{OH})_{2}$ ilave edilen peletlerin kuru mukavemet değerlerinin $725 \mathrm{~N} /$ Pelet gibi yüksek bir değere ulaştığı görülmüştür.

- Bu sonuçlara göre, $\% 2 \mathrm{CMC}, \% 20$ kok ve $\% 4 \mathrm{Ca}(\mathrm{OH})_{2}$ ilave edilerek üretilen peletlerin $200{ }^{\circ} \mathrm{C}$ sicaklıkta 90 dakika kurutulmaları sonucu elde edilen $725 \mathrm{~N} /$ Pelet mukavemet değeri soğukta sertleşen pelet standartlarının çok üzerinde bir değer olup, kromit cevher ve konsantrelerinin peletlenmesinde kullanılabilecek vasıflara sahip olduğu ortaya konulmuştur. Bu peletlerin ham pelet düşme sayılarının $25-28$ düşme $/ 45 \mathrm{~cm}$ olduğu tespit edilmiştir.

\section{Teșekkür}

$\mathrm{Bu}$ çalışma Fırat Üniversitesi Bilimsel Araştırma Projeleri (FÜBAP) yönetim birimi (Proje No: TEKF.19.13) tarafindan desteklenmiştir.

\section{Yazarların Katkısı}

Uğur ÇALIGÜLÜ Yüksek lisans tez danışmanı olup, tez ve yayın sürecini yönetmiş̧tir. Mustafa BOYRAZLI tezin deneysel çalışmalarını ve yayın sürecini yönetmiştir. Selçuk KARATAŞ: çalışmanın mikroyapı ve mekanik analizlerini yönetmiştir. Ercan ÇAKIR Yüksek lisans tez öğrencisi olup, tezin deneysel çalışmalarını ve yayın sürecini yönetmiştir. Ali KESKİN kromit cevherinin teminini sağlamış olup, peletleme işlem sürecini yönetmiştir.

\section{Çıkar Çatışması Beyanı}

Yazarlar arasında herhangi bir çıkar çatışması bulunmamaktadır.

\section{Araştırma ve Yayın Etiği Beyanı}

Yapılan çalışmada araştırma ve yayın etiğine uyulmuştur.

\section{Kaynaklar}

[1] Apaydın F., Atasoy A., Yıldız K. 2011. Mekanik aktive edilmiş kromitin grafitle karbotermal redüksiyon kinetiği. SAÜ Fen Bilimleri Dergisi, 15 (1): 17-22.

[2] Yarkadas G., Yildiz K. 2009. Effects of mechanical activation on the soda roasting of chromite. Can. Metal. Quarterly, 48 (1): 69-72. 
[3] Murthy Y.R., Tripathy S.K., Kumar C.R. 2011. Chrome ore beneficiation challenges \& opportunities a review. Minerals Engineering, 24 (5): 375e380.

[4] Yalcin S. 2003. Modelling Chromium Leaching From Chromite Ore Processing Waste. The Degree of Master of Science, the Department of Environmental Engineering, the Graduate School of Natural and Applied Sciences of the Middle East Technical University.

[5] Uyanik T. 2010. Mining, Export Promotion Center of Turkey, 9 p. Available at: http://www.fenimining.com/ upload/dosyalar/m_rapor_1359493103.pdf (Access Date: 10.07.2015).

[6] Boyrazlı M., Öztürk E.A., Benkli Y.E., Çizmecioğlu Z. 2015 Soğukta Sertleşen Pelet Üretiminde Pelet Mukavemetine Na-Bentonit ve Organik Bağlayıcıların Etkilerinin Karşılaştırılması. Metal Dünyas1 Dergisi Say1, Nisan: 262.

[7] Benkli Y.E. 2008. Soğukta Sertleşen Kompozit Peletlerin Yarı Ergitme Şartlarında İndirgenmesinin Araştırılması. Doktora Tezi, Yıldız Teknik Üniversitesi, Fen Bilimleri Enstitüsü, İstanbul.

[8] Mourao M., Takano C. 2003. Self-Reducing Pellets for Ironmakıng Mechanical Behavior. Mineral Processing \& Extractive Metall. Rev., 24: 233-252.

[9] Benkli Y.E., Boyrazli M., Senoz G.M.L., Cizmecioglu Z. 2018. Investigation of reduction of magnetite based carbon composite pellets under semi-fusion conditions. Physicochem. Probl. Miner. Process., 54 (3): 621-628.

[10] Benkli Y.E., Boyrazlı M., Avdallar V., Çizmecioğlu Z., Artır R. 2008. Organik Esaslı Bağlayıcı ile Soğukta Sertleşen Kompozit Pelet Üretiminin Araştırılması. 14. Uluslararası Metalurji ve Malzeme Kongresi, Ekim 2008, İstanbul.

[11] https://akbelkimya.com.tr/cmc-karboksimetil-seluloz-196-urun (Erişim Tarihi: 15.03.2021).

[12] Boyrazlı M. 2008. Demir Cevherleri İçerisindeki Safsızlıkların Olumsuz etkilerinin Giderilme Yollarının Araştırılması. Doktora Tezi, Yıldız Teknik Üniversitesi, Fen Bilimleri Enstitüsü, İstanbul.

[13] Boyrazlı M., Artır R., Çizmecioğlu Z. 2006. Divriği Manyetit Konsantresiyle Üretilen Küresel Peletlerde Klorlayıcı Buharlaştırma Yönteminin Alkali Giderimine ve Pelet Mukavemetine Etkisinin Araştırılması. 13. Uluslararası Metalurji ve Malzeme Kongresi, Kasım 2006, İstanbul

[14] https://en.wikipedia.org/wiki/Calcium_hydroxide (Erişim Tarihi: 15.03.2021). 